\title{
Innate lymphoid cells, possible interaction with microbiota
}

\author{
Kazuyo Moro • Shigeo Koyasu
}

Received: 15 September 2014 / Accepted: 13 November 2014 / Published online: 13 December 2014

(C) The Author(s) 2014. This article is published with open access at Springerlink.com

\begin{abstract}
Recent studies have identified novel lymphocyte subsets named innate lymphoid cells (ILCs) lacking antigenspecific receptors. ILCs are present in a wide variety of epithelial compartments and occupy an intermediate position between acquired immune cells and myeloid cells. ILCs are now classified into three groups: group 1 ILC, group 2 ILC, and group 3 ILC based on their cytokine production patterns that correspond to the helper T cell subsets Th1, Th2, and Th17, respectively. ILCs play important roles in protection against various invading microbes including multicellular parasites, and in the maintenance of homeostasis and repair of epithelial layers. Excessive activation of ILCs, however, leads to various inflammatory disease conditions. ILCs have thus attracted interests of many researchers in the fields of infectious immunity, inflammatory diseases, and allergic diseases. Because epithelial cells sense alterations in environmental
\end{abstract}

This article is a contribution to the Special Issue on Microbiome, Immunity and Inflammation - Guest Editor: Hiroshi Ohno

K. Moro $\cdot$ S. Koyasu

Laboratory for Immune Cell Systems, RIKEN Center for Integrative

Medical Sciences (IMS), 1-7-22 Suehiro-cho, Tsurumi-ku,

Yokohama 230-0045, Japan

K. Moro

Precursory Research for Embryonic Science and Technology (PRESTO), Japan Science and Technology Agency, 7 Goban-cho, Chiyoda-ku, Tokyo 102-0076, Japan

K. Moro $(\bowtie)$

Division of Immunobiology, Department of Medical Life Science, Graduate School of Medical Life Science, Yokohama City

University, 1-7-29 Suehiro-cho, Tsurumi-ku, Yokohama 230-0045,

Japan

e-mail: kazuyo.moro@riken.jp

S. Koyasu

Department of Microbiology and Immunology, Keio University

School of Medicine, 35 Shinanomachi, Shinjuku-ku,

Tokyo 160-8582, Japan cues, it is important to understand the functional interaction between epithelial cells, ILCs, and environmental factors such as commensal microbiota. We discuss in this review developmental pathways of ILCs, their functions, and contribution of commensal microbiota to the differentiation and function of ILCs.

Keywords ILC $\cdot$ Epithelia $\cdot$ Infection $\cdot$ Homeostasis . Allergy $\cdot$ Inflammation $\cdot$ Plasticity

\section{Immune cells in innate immunity}

Immune cells are divided into two categories, acquired immune cells and innate immune cells, based on their ability to recognize specific antigens. $\mathrm{T}$ cells and $\mathrm{B}$ cells recognize specific antigens by their unique antigen receptors, which are wholly dependent on recombination-activating genes (Rag1 and Rag2) for the acquisition of antigen specificities. Innate immune cells do not have specific antigen receptors and can be divided into two types, myeloid cells and innate lymphoid cells (ILCs). Although there is no clear definition for the myeloid and lymphoid classifications, it is believed that small and round cells with a high nucleus/cytoplasm ratio are lymphoid cells. The development of myeloid cells is dependent on PU.1, a member of the Ets family of transcription factors. PU.1 is not specific to myeloid cell development, however, since B cells are absent in PU.1-deficient mice [1]. Myeloid cells express pattern recognition receptors (PRRs) such as Toll-like receptors (TLRs) and C-type lectin receptors (CLRs) on their cell surface and recognize molecular structures on microbes. The major roles of these cells are phagocytosis to kill invading microbes and antigen processing to present antigens to acquired immune cells. ILCs, which are morphologically similar to T and B cells, occupy an intermediate position between acquired immune cells and myeloid 
cells. The helix-loop-helix transcription factor inhibitor of DNA binding 2 (Id2) and cytokine signaling through cytokine receptor common gamma chain $\left(\gamma_{c}\right)$ are required for the development of all ILCs. While acquired immune cells and myeloid cells work cooperatively, ILCs respond directly to cytokines from both myeloid cells and non-immune cells such as epithelial cells and play crucial roles in the protection of epithelial barriers against infections, repair of epithelial integrity, and maintenance of organ homeostasis.

Natural killer (NK) cells have long been an orphan innate lymphocyte population because they have been considered a member of lymphocytes but lack antigen receptors. In the late 1990s, another type of lymphocyte-lacking antigen receptors was found in fetal tissues. These cells play crucial roles in the differentiation of lymphoid organs such as lymph nodes and Peyer's patches and were named lymphoid tissue inducer (LTi) cells. During the last several years, new members of the ILC family have been reported from many laboratories and studies on ILCs are on the rise, resulting in reports of various ILCs in many tissues with different proposed names. To clarify the identities of ILCs and classify ILCs based on their functions, a panel of researchers within this field introduced a system for the classification and naming of ILCs and reported their proposal in Nature Reviews Immunology in 2013 [2]. In this review article, ILCs were divided into three groups: group 1 ILC (ILC1 and NK cells), group 2 ILC (ILC2s), and group 3 ILC (ILC3s and LTi) based on their cytokine production patterns that correspond to the helper T cell subsets Th1, Th2, and Th17, respectively. This classification has been generally accepted by researchers in this field, but as developmental pathways and functions of ILC subsets continue to be extensively studied, we faced some incongruities with these descriptions. For example, classical or conventional NK (cNK) cells that are classified as group 1 ILC seem to have distinct developmental pathways to other cell types within this group. Similarly, LTi cells appear to depend on different transcription factors for their differentiation among group 3 ILCs. ILC1, ILC2s, and ILC3s are all dependent on a transcription factor promyelocytic leukemia zinc finger (PLZF), but differentiation of cNK cells and LTi cells is independent of PLZF.

\section{Common and distinct differentiation pathways of ILCs}

All lymphocytes are derived from common lymphoid progenitors (CLP) in the fetal liver and adult bone marrow and are characterized by the lineage (Lin) ${ }^{-} \mathrm{c}-\mathrm{Kit}^{\mathrm{int}} \mathrm{Sca}-1^{+} \mathrm{IL}-7 \mathrm{R} \alpha^{+}$ phenotype. Knockout studies have identified the transcription factor Id 2 and cytokine signals mediated by $\gamma_{\mathrm{c}}$ as essential factors for the development of all ILCs. T and B cells develop independent of Id2 but require Rag1 and Rag2 genes for recombination of their antigen receptors. On the other hand,
Rag1 and Rag2 genes are dispensable for differentiation of ILCs. Interestingly, Yang et al. showed by fate mapping analysis that a fraction of ILC2s once expressed Rag2, demonstrating the close relationship between antigen receptorexpressing lymphocytes and ILCs [3]. It was later shown that Gata 3 is critical for the differentiation of ILC1, ILC2s, ILC3s, and LTi but not for cNK cells. Klose et al. recently reported the existence of a $\mathrm{Lin}^{-} \mathrm{Id} 2^{+} \mathrm{IL}-7 \mathrm{R} \alpha^{+} \mathrm{CD} 25^{-} \alpha 4 \beta 7^{+} \mathrm{Flt3}^{-}$progenitor population that they named common helper-like innate lymphoid cell progenitor (CHILP) capable of developing into all ILC subsets except cytotoxic cNK cells, indicating that cNK cells are distinct from other ILCs [4]. E4BP4 or NF-IL3 was originally reported as an essential transcription factor for cNK cell differentiation, but it was later shown that the lack of E4BP4 impairs the differentiation of all ILCs by the reduction of CHILP, indicating that E4BP4 also controls the differentiation of all ILCs, not only that of cNK cells. In addition, Constantinides et al. found that PLZF, which has been known to control differentiation of innate-type CD1d-restricted NKT cells $[5,6]$, is transiently expressed in CHILP during ILC differentiation. Fate mapping studies for the expression of Zbtb16, the gene encoding PLZF, showed labeling of ILC1, ILC2s, and ILC3s but not cNK cells and LTi cells [7]. Consistent with this observation, Zbtb16-deficient mice showed normal development of cNK cells and LTi cells whereas differentiation of ILC1, ILC2s, and ILC3s were variously affected. Accordingly, PLZF $^{+}$CHILP differentiates to ILC1, ILC2s, and ILC3s but not to cNK cells or LTi cells based on adoptive transfer experiments and clonal differentiation assays [7]. These recent results collectively showed that cNK cells branch out from CLP prior to differentiation of CLP to CHILP, followed by branching out of LTi before acquisition of PLZF expression by CHILP. Lineage specification of ILC1, ILC2s, and ILC3s from PLZF ${ }^{+}$CHILP takes place by acquisition of T-bet, Gata3, and ROR $\gamma$ t expression, respectively (Fig. 1a).

\section{Group 1 ILC}

Studies on group 1 ILC began with the discovery of cNK cells that exhibit cytotoxic activity against tumor cells $[8,9]$. Unlike cytotoxic T lymphocytes (CTLs), NK cells lack T cell receptors to recognize complexes of antigen-derived peptides and major histocompatibility complex (MHC). Instead, NK cells utilize CLRs to recognize various molecules expressed on target cells that are mostly induced by cellular stresses such as viral infection. NK cells also recognize self MHC molecules by a unique set of receptors acting as inhibitory receptors to suppress activation signals. Target cells of self-origin can be killed by NK cells when self MHC molecules are downregulated. This can often be observed in tumor cells and in infection by herpes viruses or when self MHC molecules are heavily modified by viral infection. It is also known that NK 
Fig. 1 Developmental pathways of ILCs. All ILCs require Id2 signaling for their development. cNK cells branch out earlier than other helper-like ILCs and LTi cells branch out from CHILP. Cell fate determination processes of ILC, ILC2s, and ILC3s from PLZF $^{+}$ILCP are still unknown, but there are two possibilities: a determined after PLZF ${ }^{+}$ILCP or b cell fate determinations are already established before or at the PLZF ${ }^{+}$ILCP stage
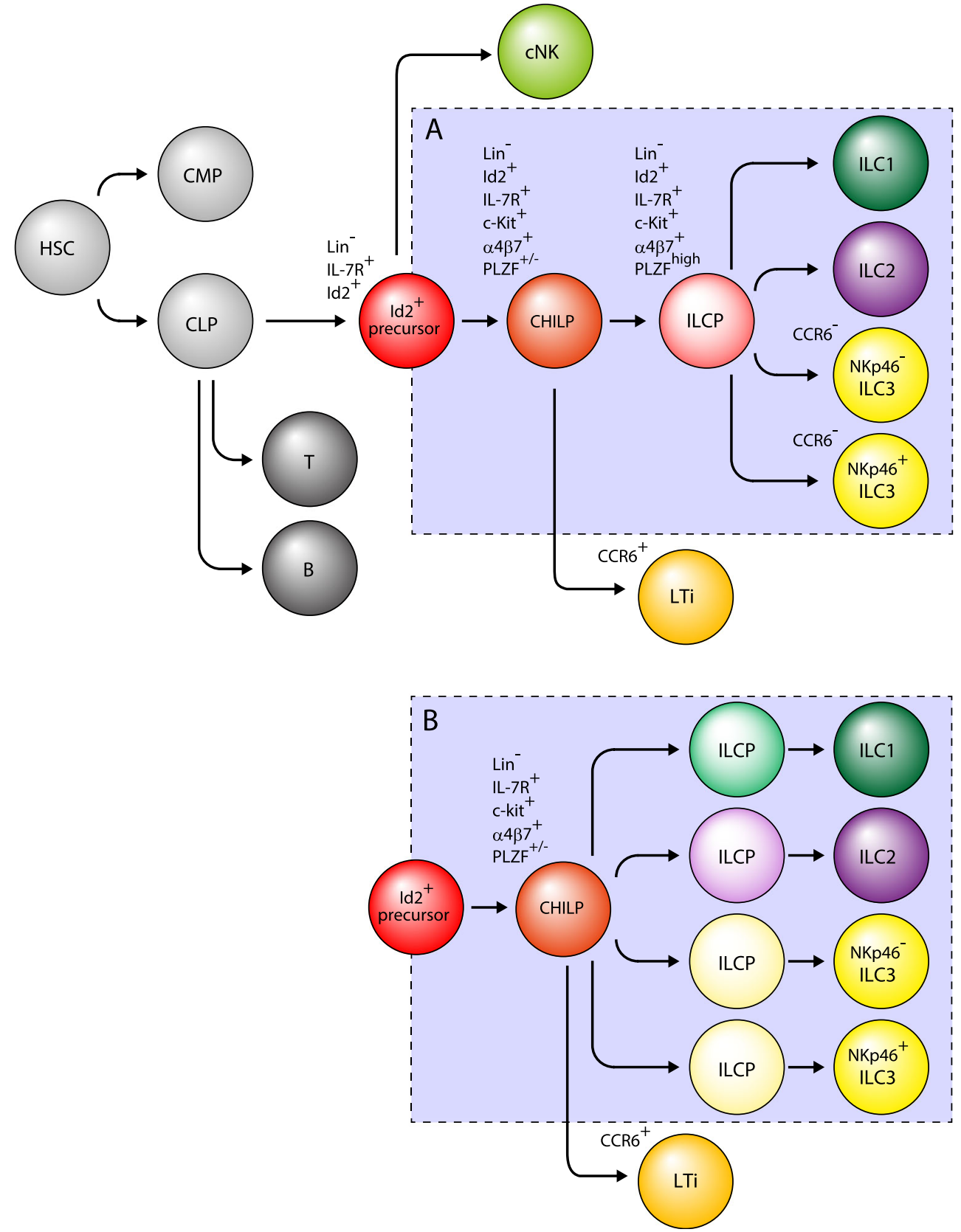

cells are potent producers of IFN $\gamma$ upon activation. Furthermore, NK cells produce IFN $\gamma$ in response to IL-12 derived from myeloid cells such as macrophages and dendritic cells, and IL-18 further enhances IFN $\gamma$ production by NK cells. NK cells thus have dual functions, namely cytotoxicity and cytokine production (Fig. 2).

NK cells express $T b x 21$ (T-bet), critical for IFN $\gamma$ expression, and secrete granules containing granzyme B and perforin, both of which induce apoptosis of target cells such as cancer cells and cells infected with intracellular microbes. Among $\gamma_{\mathrm{c}}$ cytokines, IL-15 is essential for the differentiation of cNK cells, and unlike other ILCs, IL-7 is dispensable for cNK differentiation [8]. In 2006, DiSanto and colleagues identified thymic NK cells that show less cytotoxic activity than $\mathrm{cNK}$ cells but express higher amounts of IFN $\gamma$ than $\mathrm{cNK}$ cells [10]. It was intriguing at that time that differentiation of thymic NK cells was dependent on IL-7 and Gata3 but independent of IL-15, raising the possibility that there are at least two distinct lineages for NK cells. An NK-like population that expresses T-bet and produces IFN $\gamma$ in response to IL-12 but expresses low levels of granzyme B and perforin was later reported, and this population was termed ILC1 [11]. ILC1 are present in mucosal tissues and share functional features with tissue-resident memory CD8 $\mathrm{T}$ cells that require T-bet and E4BP4 for their development and contribute to the pathophysiology of IBD [12]. While cytotoxic cNK cells express 
Fig. 2 Role of group 1 ILCs. Bacteria captured by dendritic cells (DC) induce IL-12 production to stimulate both conventional NK cells (cNK) and ILC1, both of which produce IFN- $\gamma$ and accelerate macrophage phagocytosis. cNK cells exhibit cytotoxic activity by degranulating granzyme and perforin and induce apoptosis of target cells such as infected epithelial cells

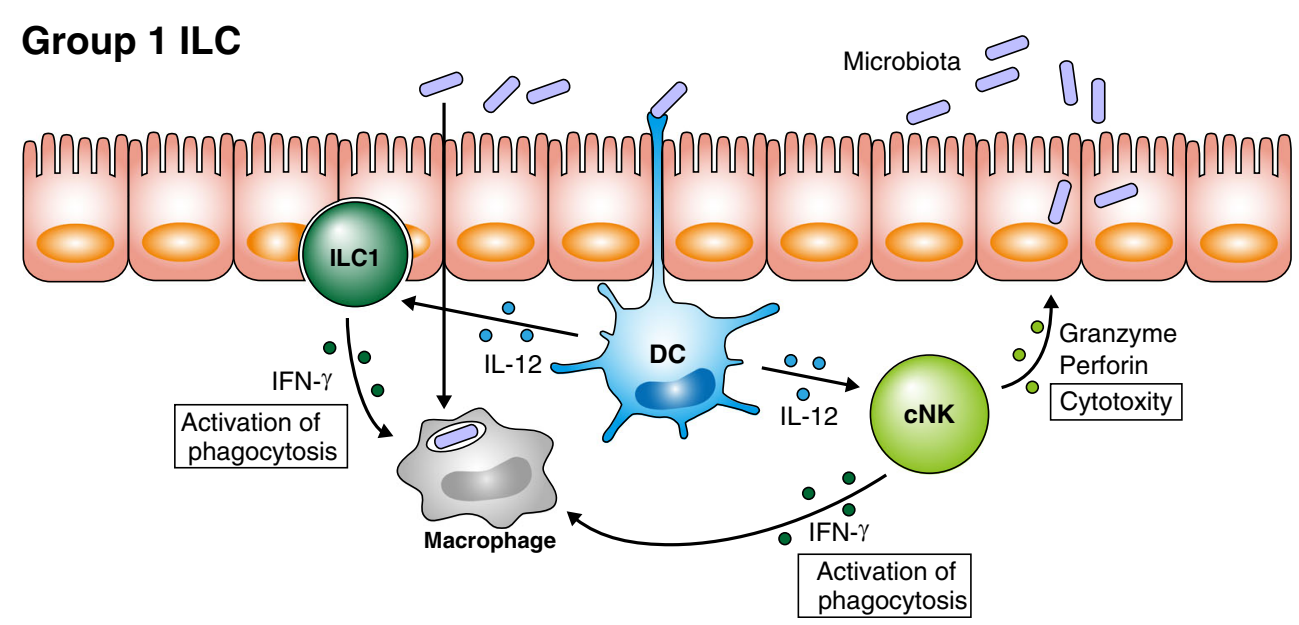

perforin, granzyme B, CD56, CD16, CD94, and NKp46, ILC1 are negative for these markers and express, CD161 and CD69, suggesting the presence of at least two phenotypically and functionally distinct populations among group 1 ILCs [11, 12] (Fig. 2).

As mentioned above, Klose et al. recently reported the existence of a $\mathrm{Lin}^{-} \mathrm{Id} 2^{+} \mathrm{IL}-7 \mathrm{R} \alpha^{+} \mathrm{CD} 25^{-} \alpha 4 \beta 7^{+} \mathrm{Flt3}^{-}$CHILP capable of developing into all ILC subsets except cNK cells, indicating that cytotoxic $\mathrm{cNK}$ cells are distinct from other helper-like ILCs [4]. Furthermore, $\operatorname{Lin}^{-} \mathrm{Id}_{2}{ }^{+} \mathrm{IL}-$ $7 \mathrm{R} \alpha^{+} \mathrm{CD} 25^{-} \alpha 4 \beta 7^{+} \mathrm{Flt} 3^{-}$progenitor cells are able to differentiate into an NKp46 ${ }^{+}$IL-7R $\alpha^{+}$ILC lineage, which have strong helper function due to IFN $\gamma$ production and are called ILC1. Both cytotoxic NK cells and ILC1 constitutively express T-bet but differ in the cytokines required for their development. cNK cells depend on IL-15 but not IL-7 [13] while all other ILCs depend on IL-7 but not IL-15. It has been reported that early pre-pro NK cells and immature NK cells express high levels of IL-7R $\alpha$ [14], but the IL-7 requirement for ILC1 is less well understood. Taken together, these results clearly define two developmentally distinct group 1 ILCs leading researchers within the field to refer to cytotoxic NK cells as cNK cells and to use the term "ILC1" to refer to $\mathrm{Lin}^{-} \mathrm{Id} 2^{+} \mathrm{IL}-$ $7 \mathrm{R} \alpha^{+} \mathrm{CD} 25^{-} \alpha 4 \beta 7^{+} \mathrm{Flt}^{-}$derived non-cytotoxic IFN $\gamma$-producing cells that have helper functions (Fig. 1). The name "group 1 ILC" is the all-inclusive term for conventional NK cells and ILC1. Moreover, the evidence suggests that the term ILC1 is likely not a suitable abbreviation for "group 1 ILC".

Microbiota are considered to be a critical factor for lymphoid organogenesis, maintenance of epithelial homeostasis, and development of acquired immune cells. Unlike acquired immune cells, cNK cells do not require commensal bacteria for their development [15]. There are indeed no differences in the expression of KLRG1, CD122, CD49b, NKG2D, and NKp46 on cNK cells between specific-pathogen-free (SPF) and germ-free (GF) housed mice. However, it has been demonstrated that expression of granzyme B and IFN $\gamma$ were significantly suppressed in GF mice as a result of lack of priming signals that mostly depend on dendritic cells (DCs). Although contribution of commensal bacteria to ILC1 differentiation and function is not well understood, a critical relationship via epithelial cells likely exists between commensal bacteria and ILC1.

\section{Group 2 ILC}

We started our work on group 2 ILC based on our finding of previously unidentified lymphoid clusters in adipose tissue, which we termed fat-associated lymphoid cluster (FALC) [16]. During the process of cellular analysis of FALC, we found a unique population of cells that express c-Kit and Sca-1 but not lineage markers. Up until that point, cells with the $\mathrm{Lin}^{-} \mathrm{c}-\mathrm{Kit}^{+} \mathrm{Sca}-\mathrm{-}^{+}$phenotype were called LSK, a cell population that contains hematopoietic stem cells and progenitor cells capable of differentiating into a variety of immune cell types. However, FALC $\mathrm{Lin}^{-} \mathrm{c}-\mathrm{Kit}^{+} \mathrm{Sca}-1^{+}$cells did not exhibit any developmental potential to other types of cells either in vivo or in vitro, suggesting that these cells are different from typical LSK cells. High expression of Th2-related genes in FALC $\mathrm{Lin}^{-} \mathrm{c}-\mathrm{Kit}^{+} \mathrm{Sca}-1^{+}$cells revealed from microarray analysis led us to reconsider the identity of this population: these cells are mature cells but not progenitor cells. A unique characteristic of this population was their ability to constitutively produce type 2 cytokines including IL-5, IL-6, and IL13. Indeed, FALC $\mathrm{Lin}^{-} \mathrm{c}-\mathrm{Kit}^{+} \mathrm{Sca}-1^{+}$cells were able to support cell division of $\mathrm{B} 1 \mathrm{~B}$ cells in a simple co-culture system, through IL-5 that is constitutively produced by this population. Furthermore, co-cultivation of FALC $\mathrm{Lin}^{-} \mathrm{c}-\mathrm{Kit}^{+} \mathrm{Sca}-1^{+}$ cells with splenic B cells resulted in the production of IgA, demonstrating the helper function of FALC $\mathrm{Lin}^{-} \mathrm{c}-\mathrm{Kit}^{+} \mathrm{Sca}-1^{+}$ cells. Type 2 cytokines are known to be important in antihelminth immunity, and it was well known that IL-5 and IL-13 are rapidly produced upon helminth infection before a 
helminth-specific adaptive Th2 response is established, demonstrating the presence of type 2 innate immune responses against helminth infection. We therefore wondered if FALC $\mathrm{Lin}^{-} \mathrm{c}-\mathrm{Kit}^{+} \mathrm{Sca}-1^{+}$cells are involved in the innate immune response against helminth infection. To demonstrate the role of FALC Lin $^{-}$c-Kit ${ }^{+} \mathrm{Sca}-1^{+}$cells in anti-helminth immunity, we focused on two previous reports demonstrating strong type 2 immune responses triggered by IL-25 and IL-33 [17, 18]. We subsequently found that IL-33 and a combination of IL-2 plus IL-25 can induce production of large quantities of type 2 cytokines such as IL-5 and IL-13 in FALC Lin $^{-}$c-Kit ${ }^{+} \mathrm{Sca}-{ }^{+}$ cells. Furthermore, we demonstrated that these cells contribute to protection against helminth infection mediated by eosinophilia and goblet cell hyperplasia. Therefore, we termed $\mathrm{Lin}^{-} \mathrm{c}-\mathrm{Kit}^{+} \mathrm{Sca}-1^{+}$cells natural helper (NH) cells based on their helper functions to both immune and non-immune cells [16].

A similar cell type, termed nuocytes, was later reported using GFP reporter mice in which GFP was inserted into the coding region of $I l 13$ gene [19]. Nuocytes were defined as $\mathrm{GFP}^{+}$cells upon administration of IL-25 or IL-33, but a corresponding population in naïve mice was obscure. Nuocytes are slightly different from NH cells because they are induced in the lymph node or spleen following IL-25 injection and express MHC class II but not CD25, unlike $\mathrm{NH}$ cells. However, the role of nuocytes is similar to that of $\mathrm{NH}$ cells in that they are also important in anti-helminth immunity. It is currently unclear whether $\mathrm{NH}$ cells and nuocytes are derived from the same lineage, and the possibility exists that nuocytes are IL-25-activated NH cells. Both cell types are current members of group 2 ILC. It is confusing that while ILC1 is a subset of group 1 ILCs, the term ILC2 is used as an abbreviated term for group 2 ILC. To clarify the distinction between subset name and group name, we recommend that group 2 ILC be called ILC2s. Following reports on the discovery of ILCs, there were a series of reports demonstrating the role of ILC2s in mice and humans [20-31]. ILC2s are localized not only in adipose tissues and lymphoid organs but also in other peripheral tissues including liver, lung, intestine, bone marrow, body cavity, dermis, and peripheral blood [23, 29, 31-35]. ILC2s are involved in anti-helminth innate immunity as well as in other conditions including, but not limited to asthma, atopic dermatitis, cancer, and hepatic fibrosis. Research toward understanding the role of ILC2s in asthma has been extensively performed. Strong type 2 cytokine production by ILC2s that results in eosinophilia and goblet cell hyperplasia is critical for the expulsion of worms during helminth infection (Fig. 3). However, induction of eosinophilia and goblet cell hyperplasia is also known to exacerbate symptoms in various allergic diseases such as asthma. Neutrophil-dominant asthma was once thought to be much more severe than eosinophil-dominant asthma, but the opposite is now considered to be true [36]. In clinical practices, the greatest difficulty encountered during asthma treatment is corticosteroid resistance, which is found in 5 to $10 \%$ of asthma patients. ILC2s are involved in the development of corticosteroid resistance through co-stimulation by IL-33 and thymic stromal lymphopoietin (TSLP), the latter of which strongly activates STAT5 and inhibits apoptosis of ILC2s [32]. While ILC2s exacerbate the severity of symptoms in asthma, amphiregulin produced by ILC2s during influenza virus infection has been shown to be important in the repair of wounded tissue, indicating that ILC2s are involved in the induction of the eosinophilic inflammatory response and tissue repair after inflammation [37] (Fig. 3).

Id2 [16], ROR $\alpha$ [38], TCF-1 [39], GATA3 [33, 40, 41, 34], Gfi1 [42], and E4BP4 [43, 44] are transcription factors that are involved in the differentiation of ILC2s, and IL-7 [16] and notch signaling [38] are requisite external factors. While defects in Id2, GATA3, and IL-7 completely impair the differentiation of ILC2s, the absence of ROR $\alpha$, TCF-1, Gfi1, and E4BP4 resulted in a marked reduction in the number of ILC2s. Interestingly, loss of Gfil resulted in inhibition of IL-33 but not IL-25-dependent expansion of ILC2s in the lung and MLN [42]. Among the above transcription factors, ROR $\alpha$ appears to be the only transcription factor that specifically regulates differentiation of ILC2s but not other ILCs. ROR $\alpha$ is highly expressed in ILC2s [16], and its deficiency greatly reduced the number of ILC2s [38, 45]. Interestingly, a small number of ILC2 cells are present in the mesentery of $\operatorname{Ror} \alpha^{\text {stg }}$ mice, a natural mutant mouse lacking functional $\operatorname{ROR} \alpha$, and these ILC2 cells produced normal amounts of IL5 and IL-13 in response to IL-33, indicating that ROR $\alpha$ is involved in the differentiation of ILC2s but dispensable for cytokine gene expression [34]. In contrast, deletion of Gata3 in mature ILC2 cells resulted in impaired production of IL-5 and IL-13 without affecting IL-6 production [34]. GATA3 binds to the promoter/enhancer region of $I l 5$ and $I l 13$ gens in ILC2 cells, and the deletion of Cgre encoding a GATA3-binding site within the $I l 13$ promoter specifically impaired the expression of IL-13 [34]. GATA3, TCF-1, and Gfil but not ROR $\alpha$ are important factors for type 2 cytokine production.

The progenitor of ILC2s was first proposed by Yang et al., demonstrating that ILC2s are CLP-derived cells [3]. Fate mapping analysis of Rag2 expression showed that a fraction of ILC2s once expressed Rag2. Subsequently, two types of ILC committed progenitors were described in fetal liver and bone marrow, Lin $^{-}$PLZF ${ }^{\text {high }}$ IL-7R $\alpha^{+} \mathrm{c}-\mathrm{Kit}^{+} \alpha 4 \beta 7^{\text {high }}$ cells and Lin Id2 ${ }^{+}$IL-7R $\alpha^{+} \mathrm{CD} 25^{-} \alpha 4 \beta 7^{+}$Flt3 $^{-}$cells [7, 4] (Fig. 1). The relationship between these two progenitors has not been elucidated. A Lin ${ }^{-}$Sca- $1{ }^{\text {hi }}$ Id2 ${ }^{\text {hi }}$ GATA $3{ }^{\text {hi }}$ cell (ILC2P) population in the bone marrow was reported to be an ILC2 specific progenitor, but this population has already acquired the ability to produce type 2 cytokines, indicating that the ILC2P population is likely immature ILC2s but not ILC2 progenitors [33]. The theory for the existence of immature ILC2s is backed by 


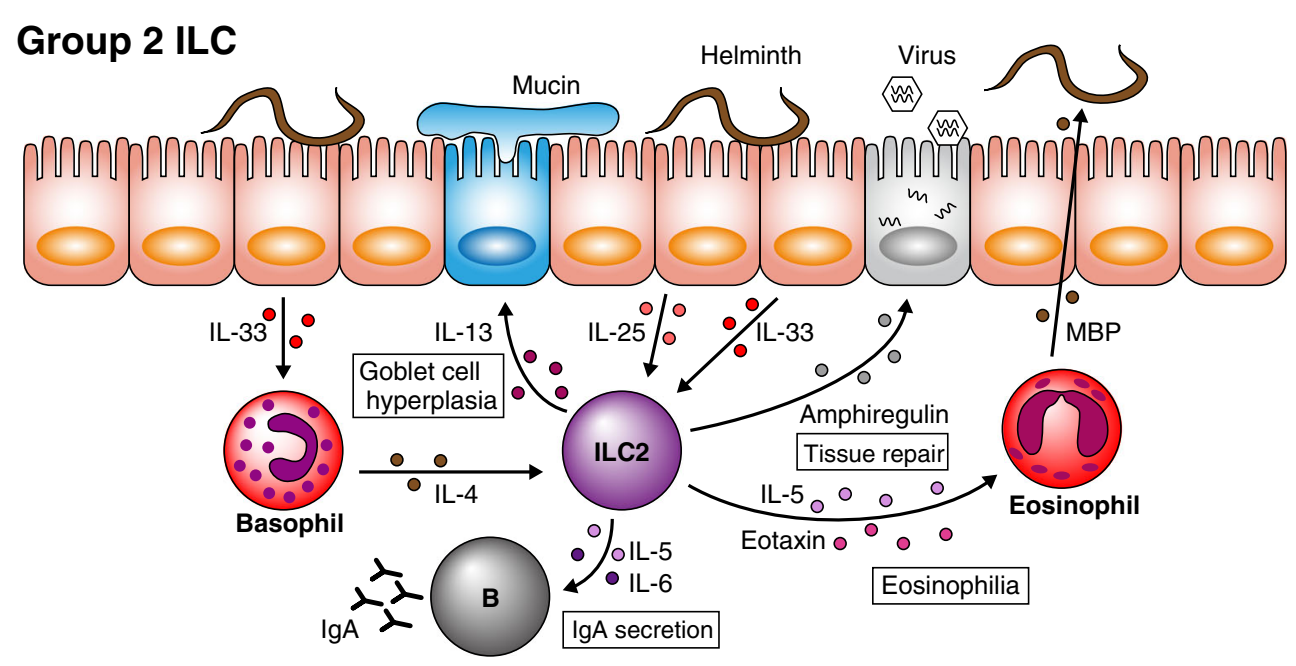

Fig. 3 Role of group 2 ILCs. In steady state conditions, ILC2s support the maintenance of IgA secretion from B cells in the intestine and B1 cell survival in the peritoneal cavity. During helminth infection, epithelial cells produce IL-25 and IL-33 to activate ILC2s, and both cytokines induce IL-5, eotaxin and IL-13 production by ILC2s. IL-5 and eotaxin are important for the expansion and migration of eosinophils, and IL-13

data that lack of Gfil resulted in the loss of ILC2P but not mature ILC2s in the lung and MLN [42].

There are currently no reports of a relationship between microbiota and ILC2s, and it is known that commensal bacteria are not required for the development of ILC2s since the number of ILC2s does not differ between germ-free and SPF mice [37]. TSLP which accelerates type 2 cytokine production by ILC2s is induced by commensal bacteria in the colon [46], however, suggesting that microbiota may play an important role in the function of ILC2s.

\section{Group3 ILC}

In 1992, Kelly and Scollay reported on a novel cell subset expressing CD4 but not CD3 in neonatal LN cells [47]. The function of this population was unclear until two research groups identified novel subsets in 1997, which were later called LTi cells: $\mathrm{CD} 4^{+} \mathrm{CD} 3{ }^{-} \mathrm{LT} \beta^{+}$cells that express $\alpha 4 \beta 7$ and are involved in the formation of lymph nodes [48] and IL-7 $\mathrm{R}^{+}$cells that induce formation of Peyer's patches $[49,48]$. During late fetal life, LTi cells produce LT $\alpha$ and LT $\beta$ in response to IL-7 or RANKL [50] stimulation and induce VCAM-1 [49, 51] and MAdCAM-1 [52] expression on lymphoid tissue organizer (LTo) cells that will later develop into LN or Peyer's patch anlagen (Fig. 4). Entry of T cells and B cells into the lymphoid anlagen to complete maturation of lymphoid tissues depends on chemokines such as CXCL13, CCL19, or CCL21 from LTo cells and is a final step of lymphocerastism. Retinoic acid-related orphan receptor $\gamma \mathrm{t}$ $(\mathrm{ROR} \gamma \mathrm{t})$ was demonstrated to be an essential factor for the development of LTi cells, and lack of ROR $\gamma \mathrm{t}$ resulted in induces goblet cell hyperplasia and mucin production. Eosinophils degranulate enzymes such as major basic protein (MBP) to attack the worm, and mucin produced by goblet cells rinses out the worm from the intestinal lumen. IL-33 also stimulates basophils in the early phase of infection to produce IL-4, which induces the initial IL-5 and IL-13 production by ILC2s

hypoplastic defects of lymph nodes and PP but not spleen, suggesting that LTi cells are involved in the formation of lymph nodes and Peyer's patches but not spleen [53]. It is currently well-known that LTi cells are not fetal-specific cells but remain in adult tissues, and are involved in the formation of secondary lymphoid tissues such as isolated lymphoid follicles (ILF) in the intestine.

During the middle of a surge in Th17 research in the mid2000's, Takatori et al. identified $\mathrm{CD} 4^{+} \mathrm{CD}^{-}{ }^{-}$LTi-like cells, an innate source of IL-17 and IL-22, which express IL-23 receptor, aryl hydrocarbon receptor (AHR) and CCR6, indicating that LTi cells are not only important for the formation of secondary lymphoid tissues but also for host defense by type 3 cytokine production [54]. Around the same time, SatohTakayama et al. also reported on a unique population that expresses NKp46 (NCR) in the small intestine [55] and is clearly different from conventional NK cells due to the lack of perforin and limited IFN $\gamma$ expression. NKp $46^{+}$cells express ROR $\gamma \mathrm{t}$ and produce sufficient amounts of IL-22 for protection against Citrobacter rodentium infection. A similar subset of cells that produce IL-22 and IL-26 following IL-23 exposure in mucosa-associated lymphoid tissues such as tonsils and Peyer's patches was characterized in a human study [56]. Collectively, these three reports suggested the presence of a unique population, which is phenotypically similar to LTi cells, but has a different cytokine profile and plays a role in microbial infection (Fig. 4).

LTi cells and IL-22 producing cells are collectively termed group 3 ILC based on the requirement for ROR $\gamma t$ for their development. While $\mathrm{CCR}^{+}{ }^{+}$LTi cells are called LTi cells, $\mathrm{CCR}^{-}$cells are generally termed ILC3s. CCR6 is an important chemokine receptor for the formation of ILFs from 


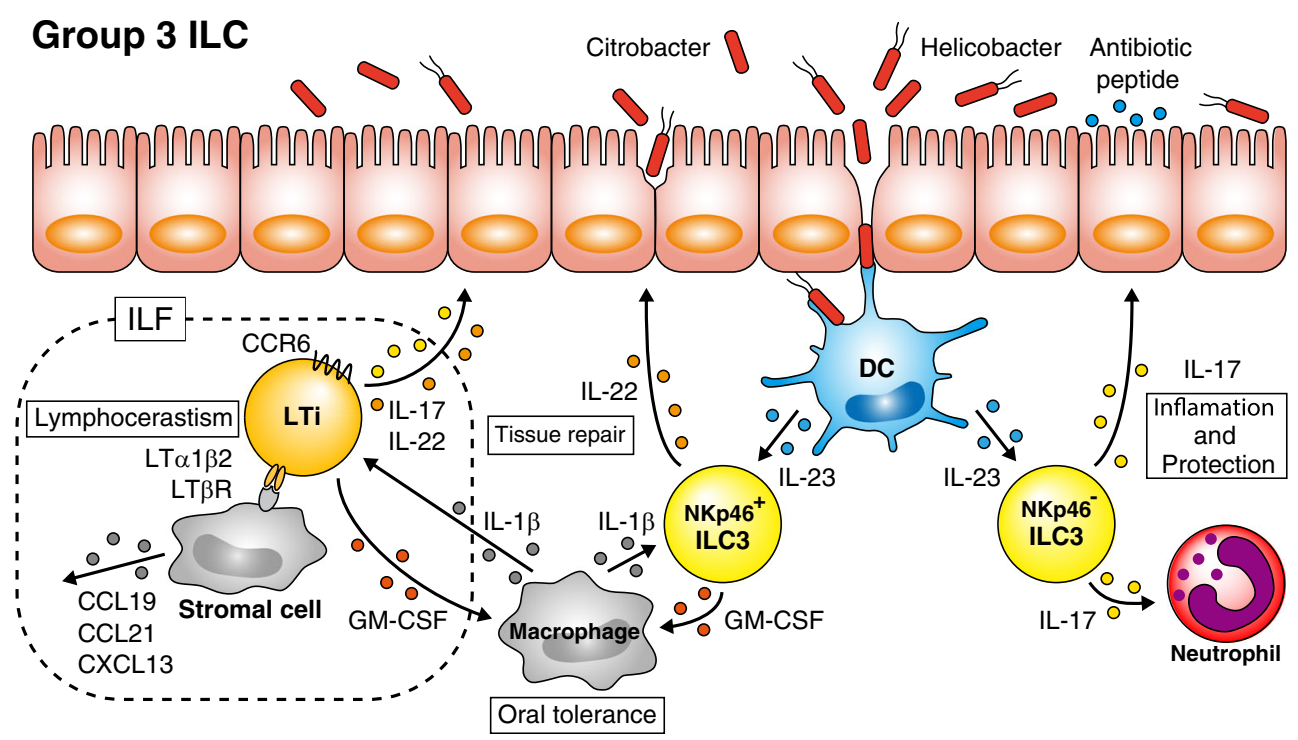

Fig. 4 Role of group 3 ILCs. In response to IL-23 produced by dendritic cells (DC), NKp46 ILC3s produce IL-17 for the activation of neutrophil migration and protection against bacteria through antibiotic peptide secretion by epithelial cells. NKp46 ${ }^{+}$ILC3s produce IL-22 for tissue repair. CCR6 ${ }^{+}$LTi cells in the isolated lymphoid follicles (ILF) interact

cryptopatches by LTi cells after birth. ILC3s can be divided into two subpopulations based on NKp46 expression. NKp $46^{+}$ILC3, once called ILC22, are exclusively localized in the intestinal lamina propria in the mouse, and a similar population has been reported in human tonsils [57]. NKp $46^{+}$ ILC3s do not produce IL-17 in response to IL-23, but produce IL-22 and function in protection against microbial infection and in tissue homeostasis and repair. On the other hand, NKp46- ILC3, which were previously called ILC17, and LTi cells, produce both IL-17 and IL-22 upon IL-23 stimulation. Furthermore, NKp $46^{+}$ILC3s require T-bet for their development whereas LTi cells develop independently of Tbet [58]. LTi cells can be divided into two subpopulations based on CD4 expression, but the difference between these subpopulations is not clear because both cells produce similar amounts of IL-22 and IL-17 and express LT $\alpha 1 \beta 2$. Similar to cNK cells in group 1 ILC, LTi cells were unique in group 3 ILC, based on their specialized effects on lymphocerastism. As mentioned, identification of a PLZF ${ }^{\text {high }}$ precursor clearly demonstrated that NK cells and LTi cells are distinct populations from ILC1, ILC2s, and ILC3s [7]. Although the positional relationship between two ILC progenitors Lin PLZF ${ }^{\text {high }}$ IL-7R $\alpha^{+} c-\mathrm{Kit}^{+} \alpha 4 \beta 7^{\text {high }}$ cells termed ILCP and Lin Id $2^{+}$IL-7R $\alpha^{+} \mathrm{CD} 25^{-} \alpha 4 \beta 7^{+}$Flt3 $^{-}$cells termed CHILP for helper-like ILCs [4] remains unclear, ILCP seem to be a more specific progenitor of the ILCs, because CHILP has been reported to be heterogeneous for expression of PLZF. Moreover, the possibility remains that ILCPs are a composite of the earliest progenitors of ILC1, ILC2s, and ILC3s, based on the result of PLZF ${ }^{\text {high }}$ single cell culture. PLZF $^{\text {high }}$ cells from fetal liver were co-cultured on OP9 stromal cells for 5-6 days, and with stromal cells via lymphotoxin (LT) and LT receptor to enhance chemokine production for lymphocerastism. Macrophages produce IL$1 \beta$ to induce GM-CSF by both LTi cells and NKp46 ${ }^{+}$ILC 3 s, which seems to be important for the induction of oral tolerance

development was assessed by flow cytometry analysis. As a result, 7 out of 500 wells developed into all three lineages, while 51 wells developed into double lineage (ILC1,2 : ILC2,3 : ILC3,1 =9:21:21) and all other wells differentiated into single ILC (ILC1 : ILC2 : ILC3 $=230: 141: 71$ ) [7]. It is possible that the $\mathrm{PLZF}^{\text {high }}$ cell fraction is a mixture of committed progenitors of ILC1, ILC2s, and ILC3s.

There is increasing evidence for crosstalk between commensal microbiota and group 3 ILC. It was controversial whether commensal bacteria are essential for the development of group3 ILC3. While some groups reported the importance of commensal microbiota for the development of NKp $46^{+}$ ILC3 [59, 55], others demonstrated commensal microbiotaindependent development of ROR $\gamma \mathrm{t}^{+}$ILC3 [60, 61], and Reynders et al. reported normal development and increased IL-22 production of NKp $46^{+}$ROR $\gamma \mathrm{t}^{+}$ILC3 in the small intestine of germ-free mice [62]. Recent report has shown that NKp46 expression is downstream of T-bet that is induced by microbiota and thus NKp46 $6^{+} \mathrm{T}^{- \text {bet }^{+}}$ILC3s are mostly dependent on microbiota [63]. In addition, CCR6 $6^{-}$ILC3s are dependent upon the microbiota, while TLi cells are largely independent of the microbiota [63]. Because it is difficult to discern whether environmental factors including commensal bacteria are involved in the differentiation, mechanisms how microbiota regulates the homeostasis of ILC3s remain to be elucidated.

Infection with Salmonella and Pseudomonas species induces IL- $1 \beta$ production by intestinal mononuclear phagocytes through the NLRC4 inflammasome pathway, which is critical for the upregulation of endothelial adhesion molecules and neutrophil recruitment in the intestine [64]. Recently, Mortha 
et al. reported that ILC3s in the isolated lymphoid follicles produce GM-CSF to promote oral tolerance in response to IL$1 \beta$ from intestinal macrophages [65]. They demonstrated that LTi cells and NKp46 ${ }^{+}$ILC3s but not NKp $46^{+}$ROR $\gamma \mathrm{t}^{-} \mathrm{NK}$ cells produce GM-CSF in steady-state conditions. GM-CSF production was absent in newborn mice, and strongly reduced by treatment with broad-spectrum antibiotics in both the small and large intestine in adult mice, suggesting that commensal bacteria are essential for this production (Fig. 4). ILC3s also play a role in epithelial cell fucosylation, which is important for the integrity of epithelial cells and protection against bacterial infection [66], indicating that both ILC2s and ILC3s are important in the maintenance of epithelial integrity.

AHR seems to play a role in ILC3 differentiation and function. $A h r$-deficient mice exhibited normal development of CCR $6^{+}$LTi cells but reduced numbers of CCR $6^{-}$ILC 3 cells $[67,61,63,68]$. Consistent with these observations, lymph nodes and Peyer's patches that are formed during fetal stages are mostly normal in $A h r$-deficient mice, whereas cryptopatches and ILF are absent in the absence of Ahr expression. Although the mechanisms by which AHR controls ILC3 differentiation are unknown, AHR may regulate genes involved in the differentiation of ILC3. For example, AHR is known to bind to the promoter of the $c$-Kit gene [69]. AHR is also known to act as a sensor of environmental cues by sensing various small molecules. AHR binds nutrientderived glucobrassicins that are contained in vegetables of the Brassicaceae family (for example, Broccoli) and drives postnatal expansion of CCR $6^{-}$ILC 3 and intraepithelial $\gamma \delta \mathrm{T}$ cells $[69,70]$. It is thus possible that phytochemicals control the development and maintenance of the immune system at the intestinal barrier surfaces.

In addition, recent studies have shown the importance of another nutrient, vitamin A, in the differentiation of ILC3s. Rar $\alpha$-deficient mice lacking retinoic acid receptor (RAR) $\alpha$ in hematopoietic cells have a reduced number of fetal LTi cell partly because RAR $\alpha$ binds the promoter region of the Rorc gene and upregulates the expression of ROR $\gamma$ t. As a result, adult Rara-deficient mice have smaller lymphoid organs and are less tolerant to viral infections [71]. Spencer et al. (2014) reported that deprivation of vitamin A in adult mice resulted in the reduction of IL-22-producing ILC3 and impaired immunity against $C$. rodentium [72]. Intriguingly, the number of ILC2s increased in these mice, demonstrating that the mechanisms balancing ILC2 and ILC3 in mucosal barrier surfaces are nutrient-dependent.

\section{Conclusion and perspectives}

We have discussed the differentiation and function of ILCs and their relationship between environmental factors including commensal microbiota. As discussed, ILCs are distributed throughout the epithelial compartment and are involved in the maintenance of epithelial integrity and protection against various invading microbes. Commensal microbiota likely play important roles in the maintenance of epithelial integrity through their effects on ILC differentiation and function. It is well known that environmental factors including commensal microbiota affect cellular characteristics through epigenetic modifications. Therefore, it is of interest to consider evidence for the possible involvement of commensal microbiota in the plasticity between distinct ILCs. IFN- $\gamma$-producing ILC1 that express the receptor for IL-7 and lack NK cell markers and lytic enzymes, arise from the conversion of ROR $\gamma \mathrm{t}^{+} \mathrm{ILC} 3 \mathrm{~s}$ under the influence of IL-12 during inflammation [11]. Similarly, ROR $\gamma \mathrm{t}^{+}$IFN- $\gamma$-producing cells can be induced from human ILC3s in vitro by culturing with IL-2 [73-75]. In mice, fate-mapping experiments showed that some IFN- $\gamma$ producing ILC1 cells are indeed derived from ROR $\gamma \mathrm{t}^{+}$ILC $3 \mathrm{~s}$ $[4,76]$. These studies collectively suggest that a certain fraction of ILC1 might stem from ILC3s. Compared to ILC1 and ILC3s, ILC2s seem to be a relatively stable subset. However, it is still possible that there is plasticity between ILC2s and other ILC subsets $[42,77]$. Crellin et al. reported that human ILC3s can produce IL-5 and IL-13 when stimulated with TLR2 ligands [77]. In addition, Spooner et al. showed that lack of the Gfil gene resulted in the loss of GATA-3 expression and coexpression of IL-13 and IL-17 [42]. They showed that Gfil suppresses the phenotypic characteristics of ILC3s through suppression of the Sox4-Rorc axis that is required for the expression of the $1117 a$ gene [42]. The mechanisms for the stabilization of the characteristics of ILCs and those driving the plasticity between distinct ILCs and involvement of commensal microbiota remain to be elucidated in future studies.

Acknowledgments We thank Kafi N. Ealey for critical reading of this manuscript and members of the Laboratory for Immune Cell Systems for discussion. This work was supported by PRESTO to K.M. from the Japan Science and Technology Agency, a Grant-in Aid for Young Scientist (A) (22689013) to K.M., a research grant from The Nakajima Foundation to K.M. and a Grant-in-Aid for Scientific Research (S) (22229004) to S.K. from the Japan Society for the Promotion of Science (JSPS), a Grant-inAid for Scientific Research on Innovative Areas (23118526) to K.M. from the Ministry of Education, Culture, Sports, Science and Technology, Japan.

Open Access This article is distributed under the terms of the Creative Commons Attribution License which permits any use, distribution, and reproduction in any medium, provided the original author(s) and the source are credited.

\section{References}

1. Chen H, Ray-Gallet D, Zhang P, Hetherington CJ, Gonzalez DA, Zhang DE, Moreau-Gachelin F, Tenen DG (1995) PU.1 (Spi-1) autoregulates its expression in myeloid cells. Oncogene 11(8): $1549-1560$ 
2. Spits H, Artis D, Colonna M, Diefenbach A, Di Santo JP, Eberl G, Koyasu S, Locksley RM, McKenzie AN, Mebius RE, Powrie F, Vivier E (2013) Innate lymphoid cells - a proposal for uniform nomenclature. Nat Rev Immunol 13(2):145-149. doi:10.1038/ nri3365

3. Yang Q, Saenz SA, Zlotoff DA, Artis D, Bhandoola A (2011) Cutting edge: natural helper cells derive from lymphoid progenitors. J Immunol (Baltimore, Md : 1950) 187(11):5505-5509. doi:10.4049/ jimmunol.1102039

4. Klose CS, Flach M, Mohle L, Rogell L, Hoyler T, Ebert K, Fabiunke C, Pfeifer D, Sexl V, Fonseca-Pereira D, Domingues RG, VeigaFernandes H, Arnold SJ, Busslinger M, Dunay IR, Tanriver Y, Diefenbach A (2014) Differentiation of type 1 ILCs from a common progenitor to all helper-like innate lymphoid cell lineages. Cell 157(2):340-356. doi:10.1016/j.cell.2014.03.030

5. Savage AK, Constantinides MG, Han J, Picard D, Martin E, Li B, Lantz O, Bendelac A (2008) The transcription factor PLZF directs the effector program of the NKT cell lineage. Immunity 29(3):391-403. doi:10.1016/j.immuni.2008.07.011

6. Kovalovsky D, Uche OU, Eladad S, Hobbs RM, Yi W, Alonzo E, Chua K, Eidson M, Kim HJ, Im JS, Pandolfi PP, Sant'Angelo DB (2008) The BTB-zinc finger transcriptional regulator PLZF controls the development of invariant natural killer $\mathrm{T}$ cell effector functions. Nat Immunol 9(9):1055-1064. doi:10.1038/ni.1641

7. Constantinides MG, McDonald BD, Verhoef PA, Bendelac A (2014) A committed precursor to innate lymphoid cells. Nature 508(7496): 397-401. doi:10.1038/nature13047

8. Kiessling R, Klein E, Wigzell H (1975) "Natural" killer cells in the mouse. I. Cytotoxic cells with specificity for mouse Moloney leukemia cells. Specificity and distribution according to genotype. Eur J Immunol 5(2):112-117. doi:10.1002/eji.1830050208

9. Kiessling R, Klein E, Pross H, Wigzell H (1975) "Natural” killer cells in the mouse. II. Cytotoxic cells with specificity for mouse Moloney leukemia cells. Characteristics of the killer cell. Eur J Immunol 5(2): 117-121. doi:10.1002/eji.1830050209

10. Vosshenrich CA, Garcia-Ojeda ME, Samson-Villeger SI, Pasqualetto V, Enault L, Richard-Le Goff O, Corcuff E, Guy-Grand D, Rocha B, Cumano A, Rogge L, Ezine S, Di Santo JP (2006) A thymic pathway of mouse natural killer cell development characterized by expression of GATA-3 and CD127. Nat Immunol 7(11):1217-1224. doi:10. 1038/ni1395

11. Bernink JH, Peters CP, Munneke M, te Velde AA, Meijer SL, Weijer K, Hreggvidsdottir HS, Heinsbroek SE, Legrand N, Buskens CJ, Bemelman WA, Mjosberg JM, Spits H (2013) Human type 1 innate lymphoid cells accumulate in inflamed mucosal tissues. Nat Immunol 14(3):221-229. doi:10.1038/ni.2534

12. Fuchs A, Vermi W, Lee JS, Lonardi S, Gilfillan S, Newberry RD, Cella M, Colonna M (2013) Intraepithelial type 1 innate lymphoid cells are a unique subset of IL-12- and IL-15-responsive IFN-gammaproducing cells. Immunity 38(4):769-781. doi:10.1016/j.immuni. 2013.02.010

13. He YW, Malek TR (1996) Interleukin-7 receptor alpha is essential for the development of gamma delta $+\mathrm{T}$ cells, but not natural killer cells. J Exp Med 184(1):289-293

14. Carotta S, Pang SH, Nutt SL, Belz GT (2011) Identification of the earliest NK-cell precursor in the mouse BM. Blood 117(20):54495452. doi:10.1182/blood-2010-11-318956

15. Ganal SC, Sanos SL, Kallfass C, Oberle K, Johner C, Kirschning C, Lienenklaus S, Weiss S, Staeheli P, Aichele P, Diefenbach A (2012) Priming of natural killer cells by nonmucosal mononuclear phagocytes requires instructive signals from commensal microbiota. Immunity 37(1):171-186. doi:10.1016/j.immuni.2012.05.020

16. Moro K, Yamada T, Tanabe M, Takeuchi T, Ikawa T, Kawamoto H, Furusawa J, Ohtani M, Fujii H, Koyasu S (2010) Innate production of $\mathrm{T}(\mathrm{H}) 2$ cytokines by adipose tissue-associated c-Kit $(+)$ Sca-1(+) lymphoid cells. Nature 463(7280):540-544. doi:10.1038/nature08636
17. Fort MM, Cheung J, Yen D, Li J, Zurawski SM, Lo S, Menon S, Clifford T, Hunte B, Lesley R, Muchamuel T, Hurst SD, Zurawski G, Leach MW, Gorman DM, Rennick DM (2001) IL-25 induces IL-4, IL-5, and IL-13 and Th2-associated pathologies in vivo. Immunity 15(6):985-995

18. Schmitz J, Owyang A, Oldham E, Song Y, Murphy E, McClanahan TK, Zurawski G, Moshrefi M, Qin J, Li X, Gorman DM, Bazan JF, Kastelein RA (2005) IL-33, an interleukin-1-like cytokine that signals via the IL-1 receptor-related protein ST2 and induces T helper type 2-associated cytokines. Immunity 23(5):479-490. doi:10.1016/ j.immuni.2005.09.015

19. Neill DR, Wong SH, Bellosi A, Flynn RJ, Daly M, Langford TK, Bucks C, Kane CM, Fallon PG, Pannell R, Jolin HE, McKenzie AN (2010) Nuocytes represent a new innate effector leukocyte that mediates type-2 immunity. Nature 464(7293):1367-1370. doi:10.1038/ nature 08900

20. Chang YJ, Kim HY, Albacker LA, Baumgarth N, McKenzie AN, Smith DE, Dekruyff RH, Umetsu DT (2011) Innate lymphoid cells mediate influenza-induced airway hyper-reactivity independently of adaptive immunity. Nat Immunol 12(7):631-638. doi:10.1038/ni. 2045

21. Ikutani M, Yanagibashi T, Ogasawara M, Tsuneyama K, Yamamoto S, Hattori Y, Kouro T, Itakura A, Nagai Y, Takaki S, Takatsu K (2012) Identification of innate IL-5-producing cells and their role in lung eosinophil regulation and antitumor immunity. J Immunol (Baltimore, Md : 1950) 188(2):703-713. doi:10.4049/jimmunol. 1101270

22. Price AE, Liang HE, Sullivan BM, Reinhardt RL, Eisley CJ, Erle DJ, Locksley RM (2010) Systemically dispersed innate IL-13-expressing cells in type 2 immunity. Proc Natl Acad Sci U S A 107(25):1148911494. doi:10.1073/pnas. 1003988107

23. Roediger B, Kyle R, Yip KH, Sumaria N, Guy TV, Kim BS, Mitchell AJ, Tay SS, Jain R, Forbes-Blom E, Chen X, Tong PL, Bolton HA, Artis D, Paul WE, de St F, Groth B, Grimbaldeston MA, Le Gros G, Weninger W (2013) Cutaneous immunosurveillance and regulation of inflammation by group 2 innate lymphoid cells. Nat Immunol 14(6):564-573. doi:10.1038/ni.2584

24. Imai Y, Yasuda K, Sakaguchi Y, Haneda T, Mizutani H, Yoshimoto T, Nakanishi K, Yamanishi K (2013) Skin-specific expression of IL-33 activates group 2 innate lymphoid cells and elicits atopic dermatitislike inflammation in mice. Proc Natl Acad Sci U S A 110(34):1392113926. doi:10.1073/pnas. 1307321110

25. Hardman CS, Panova V, McKenzie AN (2013) IL-33 citrine reporter mice reveal the temporal and spatial expression of IL-33 during allergic lung inflammation. Eur J Immunol 43(2):488-498. doi:10. 1002/eji.201242863

26. Hung LY, Lewkowich IP, Dawson LA, Downey J, Yang Y, Smith DE, Herbert DR (2013) IL-33 drives biphasic IL-13 production for noncanonical type 2 immunity against hookworms. Proc Natl Acad Sci U S A 110(1):282-287. doi:10.1073/pnas.1206587110

27. Klein Wolterink RG, Kleinjan A, van Nimwegen M, Bergen I, de Bruijn M, Levani Y, Hendriks RW (2012) Pulmonary innate lymphoid cells are major producers of IL-5 and IL-13 in murine models of allergic asthma. Eur J Immunol 42(5):1106-1116. doi:10.1002/eji. 201142018

28. Licona-Limon P, Kim LK, Palm NW, Flavell RA (2013) TH2, allergy and group 2 innate lymphoid cells. Nat Immunol 14(6):536-542. doi: 10.1038/ni.2617

29. McHedlidze T, Waldner M, Zopf S, Walker J, Rankin AL, Schuchmann M, Voehringer D, McKenzie AN, Neurath MF, Pflanz S, Wirtz S (2013) Interleukin-33-dependent innate lymphoid cells mediate hepatic fibrosis. Immunity 39(2):357-371. doi:10.1016/j. immuni.2013.07.018

30. Molofsky AB, Nussbaum JC, Liang HE, Van Dyken SJ, Cheng LE, Mohapatra A, Chawla A, Locksley RM (2013) Innate lymphoid type 2 cells sustain visceral adipose tissue eosinophils and alternatively 
activated macrophages. J Exp Med 210(3):535-549. doi:10.1084/ jem.20121964

31. Salimi M, Barlow JL, Saunders SP, Xue L, Gutowska-Owsiak D, Wang X, Huang LC, Johnson D, Scanlon ST, McKenzie AN, Fallon PG, Ogg GS (2013) A role for IL-25 and IL-33-driven type-2 innate lymphoid cells in atopic dermatitis. J Exp Med 210(13):2939-2950. doi:10.1084/jem.20130351

32. Kabata H, Moro K, Fukunaga K, Suzuki Y, Miyata J, Masaki K, Betsuyaku T, Koyasu S, Asano K (2013) Thymic stromal lymphopoietin induces corticosteroid resistance in natural helper cells during airway inflammation. Nat Commun 4:2675. doi:10.1038/ ncomms 3675

33. Hoyler T, Klose CS, Souabni A, Turqueti-Neves A, Pfeifer D, Rawlins EL, Voehringer D, Busslinger M, Diefenbach A (2012) The transcription factor GATA-3 controls cell fate and maintenance of type 2 innate lymphoid cells. Immunity 37(4):634-648. doi:10. 1016/j.immuni.2012.06.020

34. Furusawa J, Moro K, Motomura Y, Okamoto K, Zhu J, Takayanagi H, Kubo M, Koyasu S (2013) Critical role of p38 and GATA3 in natural helper cell function. J Immunol (Baltimore, Md : 1950) 191(4):1818-1826. doi:10.4049/jimmunol.1300379

35. Halim TY, Krauss RH, Sun AC, Takei F (2012) Lung natural helper cells are a critical source of Th2 cell-type cytokines in protease allergen-induced airway inflammation. Immunity 36(3):451-463. doi:10.1016/j.immuni.2011.12.020

36. Holgate ST, Polosa R (2006) The mechanisms, diagnosis, and management of severe asthma in adults. Lancet 368(9537):780-793. doi: 10.1016/s0140-6736(06)69288-x

37. Monticelli LA, Sonnenberg GF, Abt MC, Alenghat T, Ziegler CG, Doering TA, Angelosanto JM, Laidlaw BJ, Yang CY, Sathaliyawala T, Kubota M, Turner D, Diamond JM, Goldrath AW, Farber DL, Collman RG, Wherry EJ, Artis D (2011) Innate lymphoid cells promote lung-tissue homeostasis after infection with influenza virus. Nat Immunol 12(11):1045-1054. doi:10. 1031/ni.2131

38. Wong SH, Walker JA, Jolin HE, Drynan LF, Hams E, Camelo A, Barlow JL, Neill DR, Panova V, Koch U, Radtke F, Hardman CS, Hwang YY, Fallon PG, McKenzie AN (2012) Transcription factor RORalpha is critical for nuocyte development. Nat Immunol 13(3): 229-236. doi:10.1038/ni.2208

39. Yang Q, Monticelli LA, Saenz SA, Chi AW, Sonnenberg GF, Tang J, De Obaldia ME, Bailis W, Bryson JL, Toscano K, Huang J, Haczku A, Pear WS, Artis D, Bhandoola A (2013) T cell factor 1 is required for group 2 innate lymphoid cell generation. Immunity 38(4):694704. doi:10.1016/j.immuni.2012.12.003

40. Klein Wolterink RG, Serafini N, van Nimwegen M, Vosshenrich CA, de Bruijn MJ, Fonseca Pereira D, Veiga Fernandes H, Hendriks RW, Di Santo JP (2013) Essential, dose-dependent role for the transcription factor Gata3 in the development of IL-5+ and IL-13+ type 2 innate lymphoid cells. Proc Natl Acad Sci U S A 110(25):10240 10245. doi:10.1073/pnas.1217158110

41. Mjosberg J, Bernink J, Golebski K, Karrich JJ, Peters CP, Blom B, te Velde AA, Fokkens WJ, van Drunen CM, Spits H (2012) The transcription factor GATA3 is essential for the function of human type 2 innate lymphoid cells. Immunity 37(4):649-659. doi:10.1016/ j.immuni.2012.08.015

42. Spooner CJ, Lesch J, Yan D, Khan AA, Abbas A, Ramirez-Carrozzi V, Zhou M, Soriano R, Eastham-Anderson J, Diehl L, Lee WP, Modrusan Z, Pappu R, Xu M, DeVoss J, Singh H (2013) Specification of type 2 innate lymphocytes by the transcriptional determinant Gfi1. Nat Immunol 14(12):1229-1236. doi:10.1038/ni. 2743

43. Geiger TL, Abt MC, Gasteiger G, Firth MA, O'Connor MH, Geary CD, O'Sullivan TE, van den Brink MR, Pamer EG, Hanash AM, Sun JC (2014) Nfil3 is crucial for development of innate lymphoid cells and host protection against intestinal pathogens. J Exp Med 211(9): 1723-1731. doi:10.1084/jem.20140212

44. Seillet C, Rankin LC, Groom JR, Mielke LA, Tellier J, Chopin M, Huntington ND, Belz GT, Carotta S (2014) Nfil3 is required for the development of all innate lymphoid cell subsets. J Exp Med 211(9): 1733-1740. doi:10.1084/jem.20140145

45. Halim TY, MacLaren A, Romanish MT, Gold MJ, McNagny KM, Takei F (2012) Retinoic-acid-receptor-related orphan nuclear receptor alpha is required for natural helper cell development and allergic inflammation. Immunity 37(3):463-474. doi:10.1016/j.immuni. 2012.06.012

46. Mosconi I, Geuking MB, Zaiss MM, Massacand JC, Aschwanden C, Kwong Chung CK, McCoy KD, Harris NL (2013) Intestinal bacteria induce TSLP to promote mutualistic T-cell responses. Mucosal Immunol 6(6):1157-1167. doi:10.1038/mi.2013.12

47. Kelly KA, Scollay R (1992) Seeding of neonatal lymph nodes by T cells and identification of a novel population of CD3-CD4+ cells. Eur J Immunol 22(2):329-334. doi:10.1002/eji.1830220207

48. Mebius RE, Rennert P, Weissman IL (1997) Developing lymph nodes collect $\mathrm{CD} 4+\mathrm{CD} 3-$ LTbeta + cells that can differentiate to APC, NK cells, and follicular cells but not T or B cells. Immunity 7(4):493-504

49. Adachi S, Yoshida H, Kataoka H, Nishikawa S (1997) Three distinctive steps in Peyer's patch formation of murine embryo. Int Immunol 9(4):507-514

50. Kong YY, Yoshida H, Sarosi I, Tan HL, Timms E, Capparelli C, Morony S, Oliveira-dos-Santos AJ, Van G, Itie A, Khoo W, Wakeham A, Dunstan CR, Lacey DL, Mak TW, Boyle WJ, Penninger JM (1999) OPGL is a key regulator of osteoclastogenesis, lymphocyte development and lymph-node organogenesis. Nature 397(6717):315-323. doi:10.1038/16852

51. Adachi S, Yoshida H, Honda K, Maki K, Saijo K, Ikuta K, Saito T, Nishikawa SI (1998) Essential role of IL-7 receptor alpha in the formation of Peyer's patch anlage. Int Immunol 10(1):1-6

52. Eberl G, Littman DR (2003) The role of the nuclear hormone receptor RORgammat in the development of lymph nodes and Peyer's patches. Immunol Rev 195:81-90

53. Sun Z, Unutmaz D, Zou YR, Sunshine MJ, Pierani A, BrennerMorton S, Mebius RE, Littman DR (2000) Requirement for RORgamma in thymocyte survival and lymphoid organ development. Science 288(5475):2369-2373

54. Takatori H, Kanno Y, Watford WT, Tato CM, Weiss G, Ivanov II, Littman DR, O'Shea JJ (2009) Lymphoid tissue inducer-like cells are an innate source of IL-17 and IL-22. J Exp Med 206(1):35-41. doi: 10.1084/jem.20072713

55. Satoh-Takayama N, Vosshenrich CA, Lesjean-Pottier S, Sawa S, Lochner M, Rattis F, Mention JJ, Thiam K, Cerf-Bensussan N, Mandelboim O, Eberl G, Di Santo JP (2008) Microbial flora drives interleukin 22 production in intestinal $\mathrm{NKp} 46+$ cells that provide innate mucosal immune defense. Immunity 29(6):958-970. doi:10. 1016/j.immuni.2008.11.001

56. Cella M, Fuchs A, Vermi W, Facchetti F, Otero K, Lennerz JK, Doherty JM, Mills JC, Colonna M (2009) A human natural killer cell subset provides an innate source of IL-22 for mucosal immunity. Nature 457(7230):722-725. doi:10.1038/nature07537

57. Cupedo T, Crellin NK, Papazian N, Rombouts EJ, Weijer K, Grogan JL, Fibbe WE, Cornelissen JJ, Spits H (2009) Human fetal lymphoid tissue-inducer cells are interleukin 17-producing precursors to RORC+CD127+ natural killer-like cells. Nat Immunol 10(1):6674. doi:10.1038/ni. 1668

58. Rankin LC, Groom JR, Chopin M, Herold MJ, Walker JA, Mielke LA, McKenzie AN, Carotta S, Nutt SL, Belz GT (2013) The transcription factor T-bet is essential for the development of NKp46+ innate lymphocytes via the Notch pathway. Nat Immunol 14(4):389395. doi:10.1038/ni.2545 
59. Sanos SL, Bui VL, Mortha A, Oberle K, Heners C, Johner C, Diefenbach A (2009) RORgammat and commensal microflora are required for the differentiation of mucosal interleukin 22-producing NKp46+ cells. Nat Immunol 10(1):83-91. doi:10.1038/ni.1684

60. Sawa S, Cherrier M, Lochner M, Satoh-Takayama N, Fehling HJ, Langa F, Di Santo JP, Eberl G (2010) Lineage relationship analysis of RORgammat+innate lymphoid cells. Science 330(6004):665-669. doi:10.1126/science. 1194597

61. Lee JS, Cella M, McDonald KG, Garlanda C, Kennedy GD, Nukaya M, Mantovani A, Kopan R, Bradfield CA, Newberry RD, Colonna M (2012) AHR drives the development of gut ILC22 cells and postnatal lymphoid tissues via pathways dependent on and independent of Notch. Nat Immunol 13(2):144-151. doi:10.1038/ni.2187

62. Reynders A, Yessaad N, Vu Manh TP, Dalod M, Fenis A, Aubry C, Nikitas G, Escaliere B, Renauld JC, Dussurget O, Cossart P, Lecuit M, Vivier E, Tomasello E (2011) Identity, regulation and in vivo function of gut NKp46 + RORgammat + and NKp46 + RORgammat- lymphoid cells. EMBO J 30(14):2934-2947. doi:10. 1038/emboj.2011.201

63. Klose CS, Kiss EA, Schwierzeck V, Ebert K, Hoyler T, d'Hargues Y, Goppert N, Croxford AL, Waisman A, Tanriver Y, Diefenbach A (2013) A T-bet gradient controls the fate and function of CCR6RORgammat + innate lymphoid cells. Nature 494(7436):261-265. doi:10.1038/nature11813

64. Franchi L, Kamada N, Nakamura Y, Burberry A, Kuffa P, Suzuki S, Shaw MH, Kim YG, Nunez G (2012) NLRC4-driven production of IL-1beta discriminates between pathogenic and commensal bacteria and promotes host intestinal defense. Nat Immunol 13(5):449-456. doi:10.1038/ni.2263

65. Mortha A, Chudnovskiy A, Hashimoto D, Bogunovic M, Spencer SP, Belkaid Y, Merad M (2014) Microbiota-dependent crosstalk between macrophages and ILC3 promotes intestinal homeostasis. Science 343(6178): 1249288. doi:10.1126/science.1249288

66. Goto Y, Obata T, Kunisawa J, Sato S, Ivanov II, Lamichhane A, Takeyama N, Kamioka M, Sakamoto M, Matsuki T, Setoyama H, Imaoka A, Uematsu S, Akira S, Domino SE, Kulig P, Becher B, Renauld JC, Sasakawa C, Umesaki Y, Benno Y, Kiyono H (2014) Innate lymphoid cells regulate intestinal epithelial cell glycosylation. Science 345(6202):1254009. doi:10.1126/science.1254009

67. Kiss EA, Vonarbourg C, Kopfmann S, Hobeika E, Finke D, Esser C, Diefenbach A (2011) Natural aryl hydrocarbon receptor ligands control organogenesis of intestinal lymphoid follicles. Science 334(6062):1561-1565. doi:10.1126/science.1214914

68. Qiu J, Heller JJ, Guo X, Chen ZM, Fish K, Fu YX, Zhou L (2012) The aryl hydrocarbon receptor regulates gut immunity through modulation of innate lymphoid cells. Immunity 36(1):92-104. doi:10. 1016/j.immuni.2011.11.011
69. Kiss EA, Vonarbourg C (2012) Aryl hydrocarbon receptor: a molecular link between postnatal lymphoid follicle formation and diet. Gut Microbes 3(6):577-582. doi:10.4161/gmic.21865

70. Li Y, Innocentin S, Withers DR, Roberts NA, Gallagher AR, Grigorieva EF, Wilhelm C, Veldhoen M (2011) Exogenous stimuli maintain intraepithelial lymphocytes via aryl hydrocarbon receptor activation. Cell 147(3):629-640. doi:10.1016/j.cell.2011.09.025

71. van de Pavert SA, Ferreira M, Domingues RG, Ribeiro H, Molenaar R, Moreira-Santos L, Almeida FF, Ibiza S, Barbosa I, Goverse G, Labao-Almeida C, Godinho-Silva C, Konijn T, Schooneman D, O'Toole T, Mizee MR, Habani Y, Haak E, Santori FR, Littman DR, Schulte-Merker S, Dzierzak E, Simas JP, Mebius RE, VeigaFernandes H (2014) Maternal retinoids control type 3 innate lymphoid cells and set the offspring immunity. Nature 508(7494):123127. doi: 10.1038 /nature 13158

72. Spencer SP, Wilhelm C, Yang Q, Hall JA, Bouladoux N, Boyd A, Nutman TB, Urban JF Jr, Wang J, Ramalingam TR, Bhandoola A, Wynn TA, Belkaid Y (2014) Adaptation of innate lymphoid cells to a micronutrient deficiency promotes type 2 barrier immunity. Science 343(6169):432-437. doi:10.1126/science.1247606

73. Cella M, Otero K, Colonna M (2010) Expansion of human NK-22 cells with IL-7, IL-2, and IL-1beta reveals intrinsic functional plasticity. Proc Natl Acad Sci U S A 107(24):10961-10966. doi:10.1073/ pnas. 1005641107

74. Hughes T, Becknell B, McClory S, Briercheck E, Freud AG, Zhang X, Mao H, Nuovo G, Yu J, Caligiuri MA (2009) Stage 3 immature human natural killer cells found in secondary lymphoid tissue constitutively and selectively express the TH 17 cytokine interleukin-22. Blood 113(17):4008-4010. doi:10.1182/blood2008-12-192443

75. Hughes T, Becknell B, Freud AG, McClory S, Briercheck E, Yu J, Mao C, Giovenzana C, Nuovo G, Wei L, Zhang X, Gavrilin MA, Wewers MD, Caligiuri MA (2010) Interleukin-1beta selectively expands and sustains interleukin-22+ immature human natural killer cells in secondary lymphoid tissue. Immunity 32(6):803-814. doi:10. 1016/j.immuni.2010.06.007

76. Vonarbourg C, Mortha A, Bui VL, Hernandez PP, Kiss EA, Hoyler T, Flach M, Bengsch B, Thimme R, Holscher C, Honig M, Pannicke U, Schwarz K, Ware CF, Finke D, Diefenbach A (2010) Regulated expression of nuclear receptor RORgammat confers distinct functional fates to NK cell receptor-expressing RORgammat $(+)$ innate lymphocytes. Immunity 33(5):736-751. doi:10.1016/j.immuni.2010. 10.017

77. Crellin NK, Trifari S, Kaplan CD, Satoh-Takayama N, Di Santo JP, Spits H (2010) Regulation of cytokine secretion in human CD127(+) LTi-like innate lymphoid cells by Toll-like receptor 2 . Immunity 33(5):752-764. doi:10.1016/j.immuni.2010.10.012 